\title{
QUALITY MANAGEMENT SYSTEM AS TOOL FOR CORPORATE DEVELOPMENT AND COMPETITIVENESS INCREASE IN SMALL AND MEDIUM COMPANIES
}

\author{
Zane Drinke ${ }^{1}$, MBA, Ieva Bruksle ${ }^{2}$, Mag. oec.
}

\begin{abstract}
In a globalized world characterized by strong competition in various business areas, companies need to be able to find a competitive edge. Small and medium-sized enterprises, which are the backbone of the economy, must be able to compete with large companies that are technologically and financially more secure. It is therefore essential to be flexible, to look for new approaches and use different tools to promote development and competitiveness. A quality management system can be such a tool. Within the framework of this research, the role of the quality management system in ensuring successful operations and competitiveness of small and medium enterprises will be evaluated. Purpose of the methodology is to evaluate and develop four main spheres of organization: recourse management, document management, determination of management competence, efficiency and improvement management. Implementation of quality management systems or methodologies reduces corporate costs and ensures competitive operation.
\end{abstract}

Keywords: efficiency, quality, management, efficiency, competitiveness.

JEL code: M5

\section{Introduction}

In the modern business environment, the concept of quality and quality management has become an integral part of the business world and also a part of public administration. Corporate management does not have sufficient knowledge of quality management systems and understanding of benefits from corporate self-assessment. This study considers the most popular quality management system's standards and models. Models and standards have different evaluation criteria and principles, but they have a common goal - to support competitive, balanced and sustainable corporate development. The quality management system is focused on the effective use of resources and increase of productivity per unit invested. Components of the system are not an ever completed process, but a tool for corporate development. There is no single standard or model in today's business environment to assure corporate development and effective use of existing resources. There are a variety of corporate management support standards, models, systems in the world, but the criterion unifying the entire system is the satisfied customer and reduced corporate costs for ensuring competitiveness in the long-term period.

Quality management system is the object of research. Quality management system is a set of interrelated or interacting elements to establish policy and objectives and to achieve those objectives to direct and control an organization with regard to quality.

A properly developed and implemented quality system results in customer satisfaction; it is the essential support to corporate management and the institution's advantage in competition. It is not always necessary to introduce a system certified by ISO (International Organization of Standardization) standards, but one can use the methodology of the quality management system.

Objective of this study is to assess benefits from use of the quality management system in companies as an effective management tool for increasing productivity and competitiveness, optimization of financial and human resources and rational use of the available corporate resources.

Tasks to achieve the objective:

- analyse the dynamics of small and medium enterprises in Latvia and their impact on the economy;

- define the quality management system implementation trends in Latvia; 
- define benefits from quality management system application in companies by interviewing the institution's management.

The research period: $1^{\text {st }}$ November 2017 until $1^{\text {st }}$ December 2017. Due to specific and versatile nature of quality assurance and management aspects, this particular study has the following limitations: quality problems are studied, mainly, from methodological and organizational points of view; and level of education, age, social status, gender of the respondents and etc. was not taken into account in the study. Results of the managers' interviews are presented all through the content of this thesis. The following research methods are used herein: monographic or descriptive method, logical-constructive method for comparison theoretical material with the empirical results, graphical method for visual display and analysis of the summary information, document analysis for study and compiling of the internal corporate documents and questionnaires - for research of the management's and employees' satisfaction. The aim of survey was to find out the level of usage of quality management systems in enterprises. Methodological basis of the study are works of foreign (E. Deming, J. M. Juran, K. Isikava etc.) and Latvian scientists (J. Pildavs, J. Putnis, I.Reinholde), works of modern authors and publications in magazine 'Quality', which provide an insight into the latest information on trends in the field of quality management system and inform about innovations in quality management, data and reports published by the Latvian Quality Association as well as studies and statistics the International Committee for Standardization with respect to quality management system methodology and requirements.

\section{An analytical assessment of the changes in competitiveness of Latvia's small and medium enterprises}

The prevalence of small and medium enterprises in Europe and other parts of the world increased sharply after World War II. This was largely due to war damage, high unemployment, limited opportunities for state institutions to provide social assistance to citizens and the willingness of economically active people to take responsibility for their own and employment of their peers. But more attention was paid by scholars (Johnson, 1978; Lucas, 1978; Evans, D S (1985); and others) to small and medium-sized enterprises (hereinafter referred to as SMEs) only in the second half of the twentieth century, when governments of developed countries began to actively in more goal oriented manner support the formation of new enterprises. At this time, SMEs had the opportunity of receiving public financial support for overcoming threats prevalent in the external environment, for the technical modernization of enterprises and for enhancing export capacity.

At present, more than 23 million small and medium-sized enterprises that produce goods and services worth more than 4 billion Euros operate in the European Economic System. These companies employ over 90 million economically active people from different European countries (White Paper on Small and Medium Enterprises in Japan, 2016). In the European Union and in other developed countries, SME development indicators are well above the development indicators of large companies. Thus, since 2003, the number of SMEs has increased by $20 \%$ and the number of employees has increased by $24 \%$, reaching $67 \%$ of all employees. In Japan, such group of companies employs more than $80 \%$ of the workforce. (Japan's Policy on Small and Medium Enterprises and Micro Enterprises. Small and Medium Enterprise Agency. Ministry of Economy, Trade and Industry. 2013.). Moreover, in this country, the average number of employed people in SMEs is 9, more than 2 times the average development indicators of SMEs. Their distribution 
across countries and continents reflects the cultural traditions of economic activity in each of the countries and continents, as well as national efforts to promote business development in their own country, taking into account the country's most relevant traditions and experience in other countries on this issue. The results of the research on the distribution of SMEs worldwide, their impact on the country's economic development and the competitiveness of SMEs in the local and overseas markets clearly demonstrate the need to pay more attention to the problems and solutions of small and medium-sized enterprises development in Latvia, especially in the context of the region. Therefore, it is necessary to increase the number of SMEs, their efficiency, increase productivity and development of the economy as a whole.

\section{Assessment of the dynamics of economically active Latvian enterprises in the national economy}

According to the data in Table 1, the Central Bureau of Statistics of the Republic of Latvia (CSB) offers data on changes in the number of enterprises in 17 sectors of national economy. According to the context of the research, its goals and tasks 10 sectors of the national economy including 8 classified according to the NACE - 2 classification, and 2 sectors - the industry group dominated by the processing industry and the rest of the industry group were used in the analytical evaluation of statistical data. This group combines economic sectors in which the quality management system is not considered to be an essential factor for small and medium-sized enterprises operating in these sectors.

Table 1

Economically active enterprises in the national economy

\begin{tabular}{|l|c|c|c|c|c|c|c|c|c|c|c|}
\hline \multirow{2}{*}{ TSN } & \multicolumn{9}{|c|}{$\begin{array}{c}\text { Change in number of active enterprises over the years } \\
\text { (thousand) }\end{array}$} & \multicolumn{3}{c|}{$\begin{array}{c}\text { Comparison of the change } \\
\text { \% }\end{array}$} \\
\cline { 2 - 14 } & $\mathbf{2 0 0 7}$ & $\mathbf{2 0 0 8}$ & $\mathbf{2 0 0 9}$ & $\mathbf{2 0 1 0}$ & $\mathbf{2 0 1 4}$ & $\mathbf{2 0 1 5}$ & $\mathbf{2 0 1 6 *}$ & $\mathbf{2 0 1 7}$ & $\mathbf{1 7 . / 0 7 .}$ & $\mathbf{1 0 . / 0 7 .}$ & $\mathbf{1 7 . / 1 0 .}$ \\
\hline RN & 12.1 & 12.0 & 11.1 & 11.3 & 12.9 & 13.3 & 13.1 & 13.8 & 14.1 & -6.6 & 22.2 \\
\hline PT \% & $\mathrm{x}$ & -0.4 & -8.1 & 2.0 & 14.0 & 3.3 & -1.6 & 5.5 & $\mathrm{x}$ & $\mathrm{x}$ & $\mathrm{x}$ \\
\hline PKN & 42.8 & 44.1 & 43.4 & 45.5 & 45.5 & 48.3 & 50.1 & 51.7 & 20.9 & 6.4 & 13.6 \\
\hline PT \% & $\mathrm{x}$ & 3.1 & -1.5 & 4.8 & 0.1 & 6.0 & 3.8 & 3.2 & $\mathrm{x}$ & $\mathrm{x}$ & $\mathrm{x}$ \\
\hline TS & 54.8 & 56.1 & 54.5 & 56.8 & 58.4 & 61.6 & 63.2 & 65.5 & 19.4 & 3.5 & 15.3 \\
\hline PT \% & $\mathrm{x}$ & 2.3 & -2.9 & 4.2 & 2.8 & 5.4 & 2.6 & 3.6 & $\mathrm{x}$ & $\mathrm{x}$ & $\mathrm{x}$ \\
\hline
\end{tabular}

Explanation of abbreviations used in the table: RN - manufacturing sector; PKN - Service sector; TS - national economy; PT rate of increase

Source: author's calculations by using LR CSB data

The data on the dynamics of active enterprises in Table 1 and the results of calculations show that the competitiveness of enterprises operating in manufacturing sector after the crisis has changed dramatically. This is largely due to the differences in the manufactured product in various sectors of the economy and the use of these products to meet the needs of different economic participants. To a large extent, the competitiveness of enterprises was affected by support measures implemented by the government during recession. In addition, production in the manufacturing sector is more closely connected with the possibility of selling them to overseas markets, which small and medium-sized enterprises operating in the sectors used successfully by attracting money from companies in other countries.

The research first seeks to ascertain which sectors of the national economy are more attractive to start commercial activities - the manufacturing sector or the service sector. Changes in the number of new enterprises in these sectors of the national economy are shown in Table 2. 
Newly established enterprises in sectors of the national economy

\begin{tabular}{|l|c|c|c|c|c|c|c|c|c|c|c|}
\hline \multirow{2}{*}{ TSN } & \multicolumn{9}{|c|}{ Change in no. of newly established enterprises yearly } & \multicolumn{4}{c|}{ Relative change - \% } \\
\cline { 2 - 15 } & $\mathbf{2 0 0 7}$ & $\mathbf{2 0 0 8}$ & $\mathbf{2 0 0 9}$ & $\mathbf{2 0 1 0}$ & $\mathbf{2 0 1 4}$ & $\mathbf{2 0 1 5}$ & $\mathbf{2 0 1 6 *}$ & $\mathbf{2 0 1 7} *$ & $\mathbf{1 7 / 0 7}$ & $\mathbf{1 0 / 0 7}$ & $\mathbf{1 7 / 1 0}$ \\
\hline RN & 1.8 & 2.2 & 2.3 & 2.7 & 3.4 & 3.5 & 3.4 & 3.7 & 102.1 & 44.6 & 39.8 \\
\hline PT \% & $\mathrm{x}$ & 22.2 & 2.9 & 14.9 & 2.8 & 2.6 & 2.0 & 3.7 & $\mathrm{x}$ & $\mathrm{x}$ & $\mathrm{x}$ \\
\hline PKN & 9.8 & 11.8 & 16.8 & 15.7 & 16.6 & 17.2 & 17.7 & 18.3 & 86.8 & 60.0 & 16.7 \\
\hline PT \% & $\mathrm{x}$ & 20.1 & 42.7 & -6.6 & 6.3 & 3.5 & 2.9 & 3.3 & $\mathrm{x}$ & $\mathrm{x}$ & $\mathrm{x}$ \\
\hline TS & 11.6 & 14.0 & 19.1 & 18.3 & 20.0 & 20.7 & 21.3 & 22.0 & 89.2 & 57.6 & 20.1 \\
\hline PT \% & $\mathrm{x}$ & 20.5 & 36.3 & -4.0 & 5.7 & 3.3 & 2.8 & 3.3 & $\mathrm{x}$ & $\mathrm{x}$ & $\mathrm{x}$ \\
\hline
\end{tabular}

Explanation of abbreviations used in the table: RN - manufacturing sector; PKN - Services sector; TS - national economy; PT rate of increase

Source: author's calculations by using LR CSB data

The data in Table 2 convincingly point to the higher competitiveness of manufacturing sectors in attracting new entrepreneurs compared to the services sector. The increase in the number of new enterprises in this sector is more than 2 times, reaching 3.7 thousand in 2017 . In turn, in the services sector, the number of these companies has increased by 1.9 times and according to the forecast, the number of such enterprises could reach 18.3 thousand. After the crisis, the relative growth of the number of enterprises in the manufacturing sector was $39.8 \%$, which is more than 2 times higher than the level achieved by the respective indicator in the services sector - $16.7 \%$. In the meantime, during recession, the services sector was able to show a better result in attracting new companies, reaching $60 \%$, while in the manufacturing sector, the growth rate of new start-ups was lower than $25 \%$. This means that the manufacturing sector was more attractive to potential entrepreneurs to reach their goals after the crisis. In essence, this is a significant result and the trends revealed clearly indicate a positive change in the manufacturing sector, especially in the field of processing.

In Latvia, the Latvian Quality Association manages the Latvian informative system and disseminates information regarding quality management systems and their effectiveness are managed and disseminated by. The organization is to a large extent the only institution that provides knowledge of quality management systems for entrepreneurs and integrates various quality approaches in the Latvian market.

\section{Description of quality management systems in Latvia}

Quality management system consists of four main corporate areas (ISO standard requirements), which should be equivalent to efficient corporate management:

- resource management;

- document management;

- senior management responsibilities;

- corporate controls and improvement techniques (Drinke, Janovs, 2011).

Each of these areas must be particularly defined and implemented in processes in the institution. Based on the total quality management principles, there are a number of quality management models and standards developed in the world, which are aimed at excellence in performance. Excellence models and quality standards are designed as practical tools to help institutions to approach to outstanding corporate level by totally assessing actual situation, identifying strengths and weaknesses and promoting improvement and perfection. 
After introduction of the ISO, an institution can choose the most suitable development tool, Investors in Excellence or Investment Excellence (IiE), common assessment framework (CAF) developed by the European public administration, which is based on Excellence Model developed by the EFTQM - European Foundation for Quality Management (EFTQM or EFQM). The authors suggest using of this model assessment elements in the private sector as the self-assessment method to increase efficiency.

From a previous study, we conclude that in Latvia quality management system comprises four main areas of organization that need to be harmonised for effective management of the organization:

- corporate responsibility - policy, objectives, planning, quality management system;

- enterprise resource management - human resources, information, equipment

- process management - production, design, order processing, customer satisfaction;

- measurement, analysis and development - audit, process control (Drinke, Bruksle, 2017).

Open interviews with 10 senior management representatives were performed by authors. According to the results of this study gained by interviewing the senior management, selfassessment in Latvia, unlike other European countries, is carried out if any of the ISO standards or support systems is introduced. As the main benefits of quality systems, we may mention the following:

- ability to learn from the experience of successful enterprises;

- develop productivity;

- knowledge of quality policy and quality aims;

- involvement of institution employees in assessment process, thereby motivating them to "think about what and how we can do better";

- adoption of new ideas from employees about areas to be improved;

- identification of strong areas and areas to be improved on the basis of facts;

- "best practice" identification within the institution;

- ability to hear and listen to colleagues, thus contributing to a better mutual understanding;

- assessment of all processes important for institution;

- application of the resulting conclusions to further operation and resources planning;

- cost reduction;

- internal and external customer satisfaction.

Private, public administration, non-governmental institutions have the opportunity to choose the most suitable model of control system and implement it as a practical and effective tool for performance optimization. Authors of the study, who considered a number of quality management systems, guidelines and conditions acknowledge that it is not the name of management system or the new fashion trends that are important, but what positive changes can be produced in the corporate processes ensuring a better quality of services, effective communication and satisfied customers and other parties concerned, where the relationships could be described by J. Grunig and T.Hant "two-way symmetrical model, which is aimed at mutual awareness. Symmetry is achieved between the sender and recipient of the information. Two-way symmetric model contains the feedback. It is based on dialogue"(Barrie, 2002). Since 1996, a number of different Quality Management Systems were introduced in Latvia and the most popular ones are shown in Figure No. 1. 


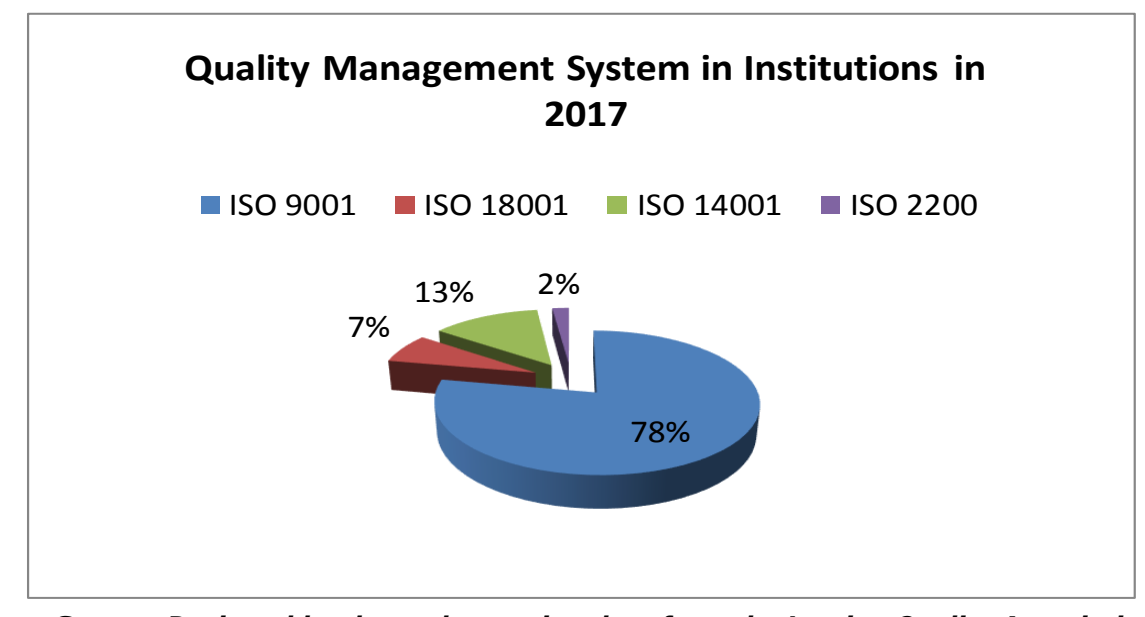

Source: Designed by the authors using data from the Latvian Quality Association

Fig. 3. Distribution of quality management systems in Latvia in \%.

Concluding, in general, there is a trend in Latvia to introduce various Quality Management Systems standards and quantity of these systems certification increases every year.

However, the implementation process is slow, which can be explained by motivation of the management and lack of knowledge about different standards and systems. According to information available to the Latvian Quality Society, in 2017, a total of 1232 companies were certified in Latvia out of which $78 \%$ are certified according to the ISO 9001 standards, and of those 528 companies, which provide services, that is $0.8 \%$ of all service providing companies in Latvia. The ISO 9001 standard system takes the largest share in Latvia, the ISO 14001 standard is the second most implemented standard. More and more companies choose to implement integrated management systems - one integrated system. There is not a single standard in the today's world, which can be simply applied to all institutions. It is also a positive fact, because opportunity is given to institutions to choose, which model to implement in their structures. However, everything is based on the level of interest in the process. If the management fails to show the initiative, there will not be any visible results. Ten countries of the world have the highest registered quantity of ISO certificates: China, Italy, Japan, Spain, the UK, the USA, Germany, India, France and Australia (Drinke, Janovs, 2011). Decrease in certified companies is valued negatively, because quality of services provided by companies could be low. Though it is assumed that introduction of a quality management system is an expensive process, benefits of the system, if it is properly introduced and used, are direct cost savings in the longer term as proved by many studies carried out in the world.

And finally, we want to note that, the results of interviews conducted with the senior management indicate the following competitive advantages for small and medium enterprises in introducing and maintaining quality management systems:

- profitability will increase on average by $15 \%$ over three years;

- productivity will increase on average by $30 \%$ over three years;

- employee satisfaction will increase;

- the number of customers will increase by $10 \%$ compared to the previous year.

\section{Conclusions and Recommendations}

Summarizing the research results, several conclusions and recommendations can be made.

1) Understanding of quality is essential for competitiveness growth in private sector. 
2) Latvian Quality Association has to carry out training, exploratory work on the benefits of different systems and opportunities to optimise the corporate resources.

3) The relatively small number of institutions that introduced the quality management system can be explained by the fact that there is no understanding of effectiveness from implementation of the model, and there is no precise definition of the corporate quality objective.

4) Common understanding of corporate objectives is achieved by ensuring total quality management in Latvian business environment.

5) Implementation of quality management systems or methodologies reduces the corporate costs and ensures competitive operation.

6) Quality awareness is essential for increasing competitiveness of the private sector businesses.

7) The number of companies that implement the various quality management systems in Latvia is small. 10 countries of the world, which have the highest number of quality management system certificates can be mentioned as examples of ensuring of efficient production. This means that a properly implemented system works effectively and can ensure sustainable development.

8) Although Latvia has a great share of small and medium-sized businesses in the total number of enterprises, it is necessary to focus on self-efficacy and promote implementation of the quality management system methodology in businesses.

9) Quality management system as tool for small and medium enterprises for competitiveness increase and it is covered by client requirements.

10) By ensuring total quality management in Latvian business environment, common understanding of the corporate objectives can be achieved leading to the promotion of national competitiveness in the international environment and increasing productivity.

11) The scientific discussion of this issue will be continued in future studies.

\section{Bibliography}

1. Barrie, G.D. (2002). Managing Quality. Fourth Edition. Oxford: Blackwell Publishing, pp. 519.

2. Drinke, Z. Total Quality Management Model in Public and Private Sector. Articles of the University of Latvia 744. Economics and Management Science. ISSN 1407-2157, 2009.

3. Drinke, Z. Bruksle, I. (2017). Quality Management System as a Global Tool for Corporate Development and Increasing Competitiveness. 17th International Scientific Conference University of Zilina "GLOBALIZATION AND ITS SOCIO-ECONOMIC CONSEQUENCES „proceedings p. 338-345.ISBN 978-80-8154-212-1

4. Drinke, Z. Janovs, V. (2011). Quality Management System as the Effectiveness of Operation Instruments. In: New values for tourism and community development: proceedings of the conference at the school of business administration Turiba. Riga: Turiba, CD-pp. 9I. ISSN 1691-6069

5. Drinke, Z. Janovs, V. (2011). Productivity and Quality management systems for the Organization Sustainable Development. Scientific article: Riga Technical University, scientific articles, series 14. "Sustainable development". RTU, Riga, volume 3, ISSN 1691-6174.

6. International Organization for Standardization (2010). About ISO, 14.09. 2010. Retrieved : http://www.iso.org/iso/about.htm. Access: 03.01.2018.

7. Japan's Policy on Small and Medium Enterprises and Micro Enterprises. Small and Medium Enterprise Agency. Ministry of Economy, Trade and Industry. 2013.

8. Juran , J.M..( 1989). Juran on Leadership for Quality. An Executive Handbook, The Press. pp. 527.

9. Latvian Quality Association ( 2010). Regarding Management Systems, 09.09.2010. Retrieved: http://www.lka.Iv/index.php?module=Articles\&cat_id=12\&view=list. Access: 12.01.2018.

10. Latvian Ministry of Economics ( 2006). Study on Promotion of Latvian Quality Policy Development. Riga: University of Latvia, pp. 89.

11. Regulations of the Cabinet of Ministers No. 501.04.12.2001. "Regulations on introduction of quality management system in public administration" Riga: MK, pp. 2.

12. Pildavs, J. (2004). Principles of Quality Management Theory. Riga: Kamene, pp. 56.

13. Putnis, J. (2001). ISO 9001:2000 Standard Interpretation. Quality.- No.1, pp. 3.

14. Reinholde, I.( 2002). Total Assessment System in the Public Administration. Quality - No. 2, pp. 2. 
Proceedings of the 2018 International Conference "ECONOMIC SCIENCE FOR RURAL DEVELOPMENT" No 47

Jelgava, LLU ESAF, 911 May 2018, pp. 65-72

DOI 10.22616/ESRD.2018.007

15. Uchikawa, S. (2009). Small and Medium Enterprises in Japan: Surviving the Long-Term Recession. ADBI Working Paper 169. Tokyo: Asian Development Bank Institute.

Retrieved: https://www.adb.org/sites/default/files/publication/156024/adbi-wp169.pdf Access: 07.02.2018.

16. White Paper on S mall and Medium Enterprises in Japan. Small and Medium Enterprise Agency. 2016.

Retrieved : http://www.meti.go.jp/english/press/2016/0422_04.html. Access: 03.01.2018. 